\title{
Modos de Subjetivação Femininos, Família e Trabalho
}

Feminine Ways of Subjectivity, Family and Work

Modos de Subjetivación Femeninos, Familia y Trabajo

Maria Cristina Lopes de

Almeida Amazonas, Luciana Leila Fontes Vieira \& Virgínia Cavalcanti Pinto

Universidade Católica de Pernambuco

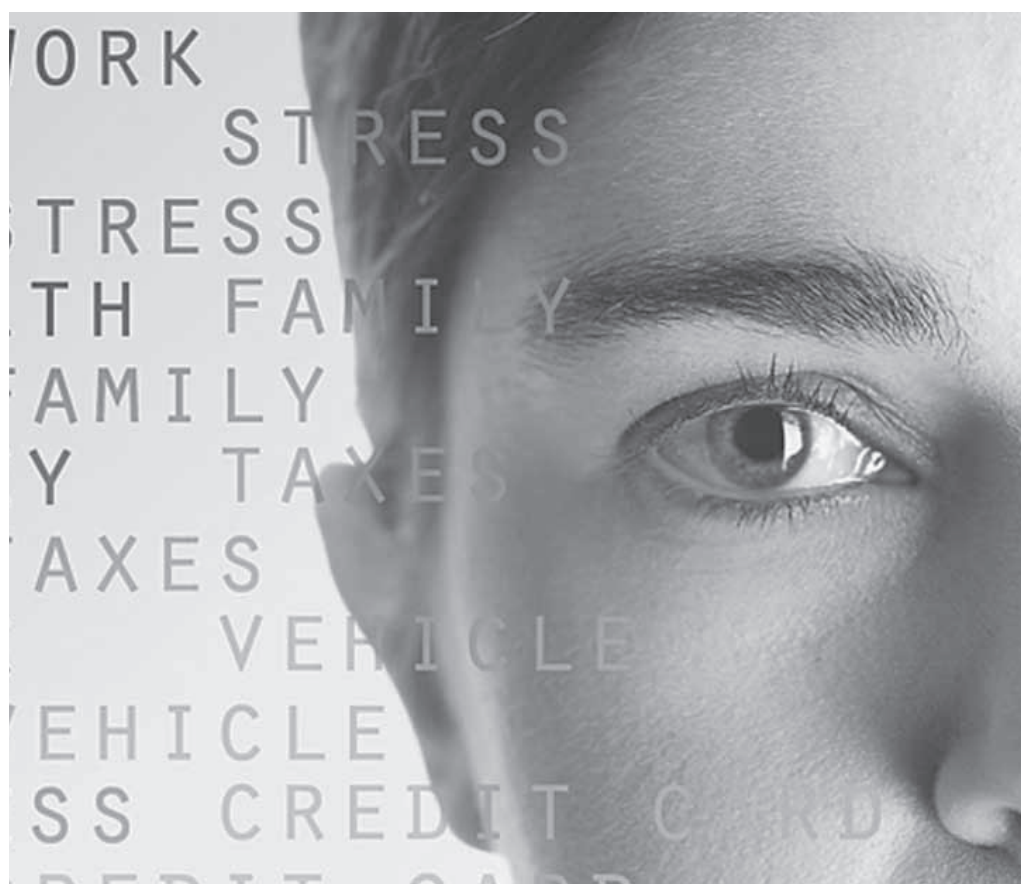


Resumo: Este artigo discute os modos de subjetivação femininos no mundo contemporâneo no contexto do trabalho e da família e problematiza o conceito de gênero tomando-o como relacional, plural, em uma tentativa de escapar à lógica binária. $\mathrm{O}$ artigo se baseia nos dados de uma pesquisa em que foram entrevistadas seis mulheres entre 25 e 35 anos de idade, de nível socioeconômico médio, cujas respostas foram submetidas à análise de conteúdo. Os resultados mostram mulheres que fazem parte de um contexto histórico que lhes endereça um discurso de sujeito autônomo e livre, que atribuem valor ao trabalho como profissão, mas que, ao mesmo tempo, são demandadas a atender as exigências de maridos e filhos no espaço privado. As múltiplas identidades que assumem requisitam posições de sujeito contraditórias, atravessadas pelas questões de gênero masculino/feminino que não mais dão conta de suas atuações no mundo. No entanto, simultaneamente, seus discursos indicam que as mulheres começam a buscar caminhos alternativos que as ajudem a superar essas relações dicotômicas.

Palavras-chave: Trabalho feminino. Gênero. Família. Dupla carreira.

\begin{abstract}
This article discusses the feminine ways of subjectivity in the contemporary world in the context of work and family. It questions the concept of gender, taking it as relational, plural, in an attempt to escape the binary logic. Data were collected from a research in which six women of medium social economic level between 25 and 35 years old were interviewed, and their answers were submitted to the content analysis. Results show women who are part of a historical context that addresses them the speech of a free and autonomous subject, who value their work as professionals, but at the same time, who are required to assist their husbands' and children's needs in private life. The multiple identities they assume require different and contradictory positions as subjects, pervaded by feminine/masculine gender issues that do not respond to their performances in the world. However, simultaneously their narrations indicate that these women have begun to look for alternative ways that might help them overcome these dichotomic relations.
\end{abstract}

Keywords: Working women. Gender. Family. Dual careers.

Resumen: Este artículo discute los modos de subjetividad femeninos en el mundo contemporáneo en el contexto del trabajo y de la familia y problematiza el concepto de género considerándolo como relacional, plural, en un intento de escapar a la lógica binaria. El artículo se basa en los datos de una encuesta en que fueron entrevistadas seis mujeres entre 25 y 35 años de edad, de nivel socio económico mediano, cuyas respuestas fueron sometidas al análisis de contenido. Los resultados muestran mujeres que hacen parte de un contexto histórico que las direcciona a un discurso de sujeto autónomo y libre, que atribuyen valor al trabajo como profesión, pero que, al mismo tiempo, se exige de ellas cumplir las exigencias de maridos e hijos en el espacio privado. Las variadas identidades que asumen necesitan posiciones de sujeto contradictorias, atravesadas por las cuestiones de género masculino/femenino que no más consiguen mantener sus actuaciones en el mundo. Sin embargo, simultáneamente, sus discursos indican que las mujeres comienzan a buscar caminos alternativos que las ayuden a superar esas relaciones dicotómicas.

Palabras clave: Trabajo de mujeres. Género. Familia. Doble carrera.

Nos dias atuais, não mais se sustenta a visão convencional pautada em uma concepção de sociedade que se caracteriza pela divisão social do trabalho, baseada na natureza biológica, que situa o homem no espaço público e confina a mulher no espaço privado do lar. A concepção de uma essência ligada ao sexo e/ou ao gênero, seja ela considerada do ponto de vista biológico, seja cultural, já foi suficientemente questionada pela literatura feminista das últimas décadas. Butler, por exemplo, afirma que:
Se o caráter imutável do sexo é contestável, talvez o próprio construto chamado 'sexo' seja tão culturalmente construído quanto o gênero; a rigor, talvez o sexo sempre tenha sido o gênero, de tal forma que a distinção entre sexo e gênero revela-se absolutamente nenhuma (Butler, 2003, p. 25)

O sexo, portanto, seria também uma construção discursiva/cultural produzida a partir de uma suposta natureza sexuada. Ele não é uma facticidade anatômica pré- 
Segundo Butler (2001, p. 161), "a construção do humano é uma operação diferencial que produz o mais e o menos 'humano,' o inumano, o humanamente impensável". discursiva, pois não há corpo que não sofra interpretações culturais e atribuição de significados (Butler, 2003). Nessa mesma perspectiva, Louro (2008) destaca que as identidades de gênero e as sexualidades são construídas através de inúmeras aprendizagens e práticas que se insinuam nas mais distintas situações, tanto de modo explícito quanto dissimulado. Há sempre um conjunto inesgotável de instâncias sociais e culturais que estão a serviço dessa construção, envoltas em um processo minucioso, sutil e sempre inacabado. Nesse sentido, o gênero pode ser considerado uma "relação política, que ocorre num campo discursivo e histórico de relações de poder" (Narvaz \& Koller, 2007, p. 217), ou seja, um efeito de linguagem produzido e gerado a partir de discursos, e não da biologia.

Dessa forma, poderíamos dizer que ser mulher, ao contrário de qualquer visão essencialista, passa pelos efeitos de formações específicas de poder que variam de uma época para outra e até na mesma época, em regiões distintas e em camadas sociais específicas. De fato, não há qualquer essência da mulher ou do homem. O próprio ato de nomeação "é uma mulher" é performativo. A performatividade não deve ser entendida como ato singular, mas como prática reiterativa, isto é, a citação repetida de uma norma que adquire autoridade na medida em que é citada como uma norma, mas que deriva seu poder das citações que impõe. Melhor dizendo, a performatividade é sempre a reiteração de uma norma ou de um conjunto de normas através da qual o discurso produz os efeitos que nomeia. A necessidade dessa reiteração se deve ao fato de que os corpos jamais se conformam totalmente às normas que Ihes são impostas (Butler, 2001). No dizer de Butler, "discursos, na verdade, habitam corpos. Eles se acomodam em corpos; os corpos (...) carregam discursos como parte de seu próprio sangue" (Prins \& Meijer, 2002, p.163).

Segundo Butler (2001, p. 161), "a construção do humano é uma operação diferencial que produz o mais e o menos 'humano,' o inumano, o humanamente impensável". Com efeito, as construções do humano produzem o lugar dos excluídos que limitam o humano e assombram suas fronteiras, aquilo que está fora, que perturba e que pode ser rearticulado.

Tomando essa perspectiva teórica, pretendemos, neste artigo, nos debruçar sobre a vida de algumas mulheres que moram no Nordeste do Brasil, enfatizando sua relação com o trabalho e com a família e considerando que as últimas décadas foram palco de intensas transformações em torno dos papéis sociais de homens e mulheres. Bruschini (2007), em uma pesquisa sobre o crescimento da atividade feminina remunerada no período de 1993 a 2005, aponta diversos fatores que contribuíram para essas mudanças, entre eles: a queda da taxa de fecundidade, principalmente nas cidades e regiões mais desenvolvidas do País, a redução do tamanho das famílias, o envelhecimento da população e maior expectativa de vida ao nascer para as mulheres em relação aos homens e, em consequência, a maior presença feminina na população idosa, além do acentuado crescimento de arranjos familiares chefiados por mulheres. A autora acrescenta a essas mudanças demográficas as transformações nos padrões culturais e nos valores relativos ao papel social da mulher, que se volta cada vez mais para o trabalho remunerado. Simultaneamente, a expansão da escolaridade e o ingresso nas universidades viabilizaram o seu acesso a novas oportunidades de trabalho. Em suma, essa configuração proporcionou o advento de uma nova identidade feminina. 
Tentaremos demonstrar que essas mulheres se situam em um tempo histórico no qual o modelo a ser seguido é o de um sujeito autônomo, independente, capaz de se autogovernar, de fazer escolhas e de se responsabilizar por elas, mas que, simultaneamente, se deparam com papéis femininos tradicionais, difundidos na sociedade, e são pressionadas a assumi-los. Esses papéis definem seus comportamentos, seus modos de vestir, de se relacionar e de se portar, e muitas vezes se apresentam como regras contraditórias. Discutiremos essas questões a partir dos relatos de algumas mulheres brasileiras, mais especificamente, nordestinas, que fizeram parte da pesquisa empírica que subsidiou este trabalho.

\section{Metodologia}

Seis mulheres foram entrevistadas, com faixa etária que variou entre 25 e 35 anos. A escolha recaiu sobre essa faixa etária por considerarmos que a exacerbada exigência profissional seja um dos efeitos de nossa época. Desse modo, as mulheres de idade superior a 35 anos, em geral, ainda vivenciaram as fases de casar e ter filhos, e até mesmo de se profissionalizar em condições distintas das que são hoje vivenciadas pelas mulheres mais jovens; para aquelas, apesar de a exigência de profissionalização já se anunciar, o nível de cobrança quanto à qualificação profissional era menos acentuado.

Das seis entrevistadas, três eram casadas e três solteiras. Das casadas, duas tinham filhos, sendo que uma delas se encontrava no segundo casamento e o filho era do primeiro marido. Todas eram integrantes da camada social média e residiam na área urbana da cidade do Recife, Estado de Pernambuco, Nordeste do Brasil. Os indicadores tomados como base para definir a camada social foram: profissão, nível de instrução, local de residência e renda familiar. Cinco das participantes tinham terceiro grau completo e uma, incompleto. Todas trabalhavam fora do lar e exerciam as seguintes profissões: Medicina, Psicologia, técnica contábil, jornalista, assistente administrativa e oficial de Justiça. Residiam em habitações confortáveis e em bairros considerados de classe média. Foram contatadas através de terceiros e apresentaram-se solícitas à pesquisa. ForamIhes atribuídos nomes fictícios para preservar suas identidades.

O instrumento utilizado foi uma entrevista aberta que começava com uma pergunta disparadora: O que é, para você, ser mulher, hoje? A partir do relato das entrevistadas, os temas e questões iam-se desdobrando.

Os encontros foram previamente marcados em locais da melhor conveniência para as respondentes. Inicialmente, explicávamos o objetivo da pesquisa e qual seria sua participação. Em seguida, antes de dar início à entrevista, que era gravada após consentimento, solicitávamos a assinatura do Termo de Consentimento Livre e Esclarecido.

Os relatos gravados foram transcritos literalmente. Após a sua leitura e releitura, analisamos o seu conteúdo (Minayo, 1999), buscando captar ao máximo possível as intenções, sentimentos, crenças e desejos explícitos e implícitos das participantes, sem perder a noção de que essa análise seria sempre uma aproximação e, como tal, incompleta. Toda a leitura do material foi simultaneamente acompanhada da releitura da teoria que, constantemente, serviu de respaldo para que essa exploração acontecesse de forma minuciosa e criteriosa. 
Segundo Louro (2003, p. 17), a luta feminista buscava inicialmente "tornar visível aquela que fora ocultada" e, certamente, podemos dizer que teve êxito.
Desse modo, a fala das participantes não aparece, aqui, apenas com caráter ilustrativo; ao contrário, seus depoimentos são convocados, invariavelmente, para estabelecer um diálogo com os pressupostos teóricos. Teoria e relatos se entrelaçam com a pretensão de enriquecer o estudo da temática, de chamar a atenção para o que é eleito hoje como modelo para se reconhecer a mulher, para compreender como elas lidam com o atendimento a esse modelo e, principalmente, para contribuir com a discussão que envolve a relação da mulher com o trabalho remunerado e a família.

\section{Apresentação e discussão dos resultados}

De acordo com Bruschini (2007), os primeiros estudos que abordaram o trabalho feminino no Brasil não consideravam que o lugar ocupado pela mulher na sociedade também estivesse determinado pelo papel que lhe é atribuído na família. Somente mais tarde foi que os debates teóricos e as pesquisas se debruçaram sobre a articulação destes dois espaços: o da produção (trabalho) e o dito da reprodução (família), uma vez que o trabalho feminino no lar, não remunerado, não era considerado produtivo. A autora afirma que, para as mulheres, ainda hoje, esses espaços estão sempre se articulando ou se superpondo, tanto no meio rural quanto no urbano. Vejamos a colocação de uma das entrevistadas:

(...) A mulher, diferente do homem, tem sempre que cuidar mais dos filhos (...), cuidar da casa (...), por isso que, hoje em dia, as mulheres estão estressadas demais... porque o homem... é aquela história: o homem tem que colocar o dinheiro em casa e a mulher fica em casa, mas não é..., porque ela tem que dividir. Além de ser mãe, ela tem que ser profissional também (Talita, psicóloga, 26 anos).
Segundo Louro (2003, p. 17), a luta feminista buscava inicialmente "tornar visível aquela que fora ocultada" e, certamente, podemos dizer que teve êxito. No entanto, vencida essa etapa, verificamos que ainda há muito a fazer.

O discurso endereçado às mulheres, hoje, exorta-as a assumir posições de sujeitos livres e autônomos. O endereçamento, porém, "consiste na diferença entre o que pode ser dito - tudo o que é histórica e culturalmente possível e inteligível de se dizer - e o que é dito" (Ellsworth, 2001, p.47), e envolve a mensagem e o sujeito que a recebe, a expectativa e o desejo. Ao receber o conteúdo da mensagem, o sujeito redireciona aquilo que lhe é enviado a partir de suas próprias posições de sujeito, determinadas por raça, classe social, nível cultural, etc:

\section{Desde pequena, eu fui criada para ter minha casa, ser uma esposa que faz tudo em casa, que arruma, cuida dos filhos (...); eu tinha que arrumar um marido para cuidar de mim (...) só que, no mundo de hoje, não cabe mais uma mulher desse tipo (Talita, psicóloga, 26 anos).}

Há uma defasagem entre aquilo que lhe é endereçado pela educação recebida e o que se espera de uma mulher no mundo atual, assim como entre o que lhe é endereçado e o modo como ela redireciona o que recebe. Não é esse tipo de mulher tradicional que Talita deseja ser. Embora tenha sido ensinada a agir de acordo com determinados padrões sociais distintos daqueles atribuídos aos homens, sente-se confusa em um mundo em que estes estão mudando, mas, ao mesmo tempo, não se conforma às antigas normas:

O que eu corro atrás é o seguinte: trabalhar, ter minha vida profissional, reconhecimento 
e ter a minha vida pessoal, familiar. Eu quero constituir uma família. Quero ser mãe, amante, esposa e quero ser companheira, tudo ao mesmo tempo. Eu acho que mulher é um pouco disso hoje em dia, essa é uma opinião bem pessoal.

Butler afirma que as pessoas só se tornam inteligíveis, inclusive para si mesmas, no interior de identidades de gênero conformadas com padrões sociais reconhecíveis como pertencentes àquelas identidades, isto é, o que é ser homem ou ser mulher em uma determinada cultura. Mas a identidade de gênero não esgota as possibilidades de ser de um sujeito. Ser mulher ou ser homem não é tudo o que uma pessoa pode ser. Outras identidades são possíveis, nem sempre coerentes entre si. "O gênero estabelece interseções com modalidades raciais, classistas, étnicas, sexuais e regionais discursivamente constituídas" (Butler, 2003, p. 20). Dessa forma, não é possível "separar a noção de gênero das interseções políticas e culturais em que invariavelmente ela é produzida e mantida".

(...) Eu sou anestesista e tô aqui neste recinto doze horas direto. Saio de manhã cedo de casa e só saio daqui à noite. Eu tô assim três vezes por semana. Eu consigo organizar minha filha até as seis e meia da manhã. Ela vai para a escola e eu vou para o hospital, porque tenho que estar lá às sete horas. Ela fica na escola e chega às onze e meia, então fica sozinha com a empregada e nós (ela e o marido) ficamos monitorando por telefone. UMA CRIANÇA DE TRÊS ANOS (ênfase). Então assim, eu vivencio perdas na minha vida pessoal! (Denise, médica, 32 anos).

Quais são as perdas de que fala Denise? Podemos pensar que há toda uma rede de poder, formada por diferentes dispositivos disciplinares (a família, a escola e o trabalho, entre outros), que atravessa os discursos acerca do que é ser homem e ser mulher e do lugar que cabe a cada um no mundo. À verdadeira mulher, parece ainda acreditar
Denise, caberia cuidar pessoalmente da casa e dos filhos e, portanto, deixar um filho aos cuidados de terceiros, mesmo que apenas parte do dia, implicaria perdas para ambos, mãe e filho. Porém, diferentemente de outras épocas, marido e mulher, pai e mãe, sentemse responsáveis pelo monitoramento dos filhos. Denise, ao contrário das mulheres de décadas anteriores, tem uma vida profissional ativa e exerce uma função antes delegada quase exclusivamente aos homens, a Medicina. E, em sua organização familiar, não apenas ela, mas também seu marido se responsabiliza pela supervisão dos cuidados da filha à distância, por telefone.

Uma das saídas que pais e mães adotam hoje é lançar mão do que poderíamos chamar de substitutos da família ou redes de apoio. Esses substitutos da família ou das tarefas que antes eram delegadas exclusivamente à mulher são as creches e a escola, entre outros. Essas instituições possibilitam que ambos, pai e mãe, possam se dedicar ao trabalho remunerado sem que isso prejudique os cuidados que toda criança necessita e tem direito; a esse respeito, Jablonski (2010, p.265) acrescenta o papel das babás e empregadas domésticas como uma peculiaridade do Brasil:

\footnotetext{
No Brasil, babás e empregadas domésticas fazem uma diferença no sentido de suprir em parte a ausência das mães que se dedicam mais intensamente ao trabalho fora de casa, ainda que haja dúvidas quanto ao número real de lares que incluem a presença de empregadas domésticas.
}

Mas é importante ressaltar que adotar esses mecanismos ou estratégias para sustentar novas identidades não é algo que acontece de modo tranquilo. Essas transformações no cotidiano das famílias são vistas, muitas vezes, como desestruturantes, e afirma-se, frequentemente, que a família está em crise. 
Foucault (citado em Castro, 2009, p.116) afirma que, quando a família entra em crise, quando as mulheres não desempenham mais suas antigas funções, surge "uma série de mecanismos disciplinares para remediar essa situação". Mas isso não funciona apenas pela normatização; ocasiona, também, o surgimento do que esse autor denomina função-psi, "função psiquiátrica, psicopatológica, psicossociológica, psicocriminológica, psicanalítica" (p. 116), e acrescentaríamos psicopedagógica. Para Foucault, a função não significa apenas o discurso veiculado socialmente mas também a instituição e o indivíduo psicologizado em si mesmo, isto é, a relação entre o discursivo e o não discursivo, as práticas. Em outras palavras, se uma mulher, tal como Denise, não consegue atender ao discurso do que é ser uma boa mãe, experimenta o sentimento de que está perdendo alguma coisa e fazendo com que ocorra o mesmo com o filho; adota uma nova prática, mas ainda não se sente confortável com ela.

Podemos dizer que, no caso de Denise, é adotado o que Araújo e Scalon (2006) denominam "modelo dual". Nesse modelo, as mulheres permanecem como as principais cuidadoras, mas transitam entre o espaço doméstico e o público, o que constitui um dado contemporâneo.

É a incompletude essencial das categorias de Mulher e Homem, porém, que permite que essas mulheres se tornem espaços disponíveis para diversos e novos significados. Nesse sentido, concordamos com Butler (2003, p. 37) quando afirma que o gênero "é uma complexidade cuja totalidade é permanentemente protelada, jamais plenamente exibida em qualquer conjuntura considerada". No entanto, concepções acerca de uma essência de homens e mulheres baseadas na natureza ou na cultura ainda prevalecem hoje, e escondem relações de poder assimétricas entre os sexos. Foucault alerta que devemos compreender o poder como "uma rede de relações sempre tensas, sempre em atividade". Ele se assemelharia mais a uma "batalha perpétua do que ao contrato que faz uma cessão ou uma conquista que se apodera de um domínio" (Foucault, $1977 / 2009$, p. 29). Vale salientar que o poder sempre se dá entre pessoas que são capazes de resistir, ou seja, nas relações de poder, há sempre um enfrentamento constante e perpétuo (Foucault, 1979/2006). Contudo, não podemos desconsiderar "o fato de que as mulheres (...) tenham mais freqüentemente e fortemente sofrido manobras de poder que as constituem o outro, geralmente subordinado e submetido - mas tais manobras não as anularam como sujeitos" (Louro, 2003, p. 40).

Porque é engraçado, o homem chega em casa, tá cansado, vai dormir. A mulher chega em casa cansada e vai ver se o menino fez a tarefa, vai ver se as coisas estão prontas; quando tem uma coisa errada, é a mulher que tem que resolver. Então, assim, meu irmão diz que eu estou errada. Na verdade, eu não sei, é uma teoria que... eu não sei, é uma vida ideal... a mulher ser independente, trabalhar um expediente e ter outro pra cuidar de outras coisas, porque é um tempo de que ela necessita. Ele (o irmão) diz que ele também trabalha, ele é advogado, também é professor, mas eu digo que, quando ele quer trabalhar, ele se tranca dentro do seu escritório e os meninos que endoidem, MAS UMA MÃE NÃO FAZ ISSO! (Denise, médica, 32 anos).

Araújo e Scalon apontam como um dos resultados de sua pesquisa acerca do sentido do trabalho doméstico para mulheres e homens uma crescente aceitação do trabalho remunerado como parte constitutiva da vida da mulher, porém essa aceitação, dizem as autoras, "vem acompanhada da permanência da valorização da domesticidade feminina, 
particularmente de seu aspecto maternal", principalmente pelos homens (2006, p. 49). Apesar de as mulheres serem o alvo mais frequente dos agenciamentos de poder, é preciso argumentar que homens e mulheres sofrem prejuízos quando orientados por uma concepção essencialista que relaciona determinados papéis ao sexo. A suposta superioridade social usufruída pelos homens acarreta inúmeras perdas para eles; uma delas é a da guarda dos filhos em caso de separação. Mas é preciso dizer que ambos, homens e mulheres, se envolvem nessas relações de poder. A relação entre os sexos não é uma via de mão única, pois o poder se exerce em várias direções (Arán, 2006). O problema parece que se encontra no modo de pensar os conceitos: masculino/feminino, igualdade/diferença como opostos, quando, na verdade, são conceitos interdependentes que estão necessariamente em tensão (Scott, 2005).

A ideia de uma identidade feminina relacionada à maternidade como um fato sagrado e inquestionável, próprio da natureza feminina, é outro dado que se apresenta com muita força nessas mulheres:

Pra mim, a mulher é uma coisa que já vem da Bíblia. É a mãe, é o amor. A mulher mesmo é uma pessoa amável, lutadora (...) Para mim, mulher é uma coisa muito boa, é o amor, a compreensão (Angélica, assistente administrativa, 35 anos).

Esse tipo de enunciado é, cotidiana e recorrentemente, apresentado às mulheres como se fosse parte de sua natureza. Sua repetição transmite valores e atributos de mães e pais, transformando-se em representações da maternidade que já pertencem ao senso comum, de tal modo que deixamos de reconhecê-las como tal e passamos a encará-las como verdades, como aquilo que deve ser a mãe, o pai. "Além disso, ou exatamente por isso, eles também norteiam mulheres e homens e/ou mães e pais de determinados tipos, e sua força reside, justamente, nas múltiplas, sutis e sempre renovadas possibilidades de sua repetição" (Meyer, 2003, p. 34).

\begin{abstract}
Eu tenho esse sonho de ser mãe, de ter uma casa, mas eu fico pensando em como é que vai ser, eu o dia todo trabalhando, e quem é que vai criar o meu filho? Uma babá? Esse é um defeito que tem a sociedade hoje, assim pela mulher ter que passar um dia inteiro fora, então ela não tem muita presença com o filho e isso me preocupa. Assim, eu não abdico disso, mas eu fico em dúvida e acho que vou ter que fazer como todas fazem: ter que trabalhar e deixar o filho com outra pessoa, mas esse é um grande medo que eu tenho: de até que ponto a sociedade chega que você não tem outra escolha (Adriana, técnica contábil, 25 anos).
\end{abstract}

Sobre as questões que envolvem a maternidade e o modo de cuidar das crianças, Meyer (2003, p. 37) afirma que, na atualidade, as inovações tecnológicas e as conquistas do movimento feminista fizeram de seu exercício uma tarefa ainda mais complexa e difícil. "Nesse contexto, gerar e criar filhos 'equilibrados e saudáveis' passa a ser social e culturalmente definido, também, como um 'projeto' de vida (...)". A respeito desse tema, a mesma autora cita Forna: Na década de 60 , as feministas
repudiaram a visão super-romanceada da
maternidade, identificando nela os laços
de seda da opressão (...). Um descuido
por parte do movimento feminista como
um todo foi ignorar a maternidade a
partir de então, acreditando que, se
toda a energia política fosse dedicada a
aumentar as possibilidades de escolha
profissional das mulheres no sentido de
alcançar a independência econômica,
a maternidade acharia um modo de se
resolver. (...) Na verdade, a história de
como o feminismo deve lidar com as 
questões em torno da maternidade está apenas começando (1999, p. 21).

Nesta pesquisa, porém, não são apenas temas que envolvem os cuidados com a casa, com a maternidade, com os filhos e com a profissão que as mulheres trazem em seus relatos, mas também o fato de experimentarem contradições no que diz respeito à vivência da conjugalidade. Embora a profissão tenha assumido um lugar de destaque na sua vida, em momento nenhum elas admitem construir uma vida solitária, sem um companheiro; ao contrário, buscam encontrar um parceiro que, do mesmo modo que elas, seja independente, respeite e incentive seu desenvolvimento profissional e, sobretudo, que divida a responsabilidade com a criação dos filhos e com a manutenção do lar. Esse parece ser o retrato do novo Príncipe Encantado. Isso nos leva à noção de formas de subjetivação "que nos permitem pensar não apenas em rupturas e continuidades com uma época anterior, como também em uma forma sempre provisória de estar no mundo, rompendo assim com a noção metafísica de identidade fixa" (Arán, 2006, p. 13).

Estar no meio disso (exigências profissionais) também depende muito do parceiro que se tem, então eu acho que eu tenho sorte, porque tenho uma pessoa do meu lado que me incentiva, que me acompanha, que mergulha nas minhas ideias, por mais loucas que sejam, que está sempre lá, me dando o apoio, então dá pra ficar nesse meio. Se eu não tivesse uma pessoa assim, com certeza, eu não conseguiria (Lúcia, jornalista, 25 anos).

Arán (2006, p.16) afirma que, se na época em que a psicanálise foi construída, a questão crucial era "o que quer a mulher?," hoje, a questão que nos colocamos é "como pensar a diferença de sexos?" Tomar o masculino como referência e modelo de dominação a partir do qual a mulher se posiciona como objeto é substituído por novas formas de sociabilidade que trazem mudança significativa ao modo de vida dos indivíduos. Essas mudanças se devem, principalmente, "à crise da família burguesa, à entrada da mulher no mercado de trabalho, à separação da sexualidade da reprodução e a uma política de visibilidade da homossexualidade" (Arán, 2006, p. 17). (...) Tais fenômenos deslocaram as fronteiras homem-público e mulher-privado e provocaram uma crise nas referências simbólicas que organizam a sociedade moderna (Arán, 2006).

Segundo a mesma autora, o trabalho feminino deixou de ter o significado que lhe era atribuído nos anos 60 e 70 do século passado, isto é, um segundo salário, e passou a constituir um valor e a corresponder a um desejo de autonomia para as mulheres.

Eu teria que aceitar um homem que aceitasse a minha independência, que ele vivesse bem com isso e não se assustasse com o fato de eu ganhar meu dinheiro e até de ganhar mais do que ele, quem sabe? Ter um trabalho que eu ganhe mais do que ele e ele aceitar bem isso, não se sentindo inferior. Hoje eu vejo muitos relacionamentos que não dão certo por conta do preconceito, porque hoje as mulheres estão tendo colocações melhores e, muitas vezes, o homem tem a ignorância de achar que a mulher o está traindo, porque a mulher tem uma colocação melhor do que a dele. Então, os homens se sentem inseguros por conta disso, então eu tenho que achar um homem que entenda isso, porque eu estou batalhando para ganhar melhor do que muitos fichinhas por aí (Adriana, técnica contábil, 25 anos).

Desse modo, podemos dizer que a divisão sexual do trabalho homem-público e mulher-privado, ainda que não tenha sido completamente modificada, "está no mínimo sob pressão" (Arán, 2006, p. 21). Entretanto, 
mesmo que o trabalho remunerado fora do lar possa ser considerado um valor constituinte da nova identidade feminina, há aspectos dessa mesma identidade que se mostram contraditórios. Um deles é o que diz respeito à participação masculina nos cuidados do filho. Algumas das mulheres ouvidas por nós reivindicam essa participação efetiva, mas, quando isso acontece, apresentam certo desconforto.

Ela (a filha) não dorme na casa de ninguém, porque ela sempre dormiu com ele (o pai). Às vezes era mais fácil - que é um ponto que a gente sente enquanto mãe- ela dormir com ele do que comigo, porque ela dormia mais com ele do que comigo, porque eu dava três plantões noturnos por semana. Aí quando eu estava em casa e ele chegava, ela não queria ficar comigo, ela queria ficar com ele (Denise, médica, 32 anos).

A lógica binária impõe uma polaridade rígida aos gêneros que é necessário desconstruir. Para tanto, precisamos observar que cada polo (masculino/feminino) contém o outro e viceversa, além de tomá-los como fragmentados e divididos internamente, pois existem várias formas de ser homem e de ser mulher que nem sempre são idênticas entre si, pelo contrário, são muitas vezes paradoxais.

A mulher contemporânea está dividida entre ser uma profissional competente e corresponder ao que ainda se espera de uma mulher como mãe; deseja que o homem compartilhe com ela as atividades domésticas e os cuidados com os filhos, porém, quando isso acontece, sente-se ameaçada.

É horrível, né? Parece que você fica sendo rejeitada, mas você tem que aprender a conviver e entender que ela (a filha) era acostumada a dormir com ele... Até hoje ela dorme bem com ele (Denise, médica, 32 anos).
Assim, quando o homem participa mais do mundo doméstico, quando divide o cuidar dos filhos com a mulher, avança em seu espaço e ameaça o seu poder. Ainda que as mulheres desejem dividir essa sobrecarga de trabalho, não desejam abrir mão do poder que usufruem. Tal poder decorre de uma crença na essência ou na natureza feminina: só elas sabem cuidar dos filhos. Por mais que o homem ajude ou participe desse cuidado, é ela quem detém o saber sobre o cuidar.

(...) Ele (o marido) nunca reclamou muito, reclama assim, no fim de semana (quando ela dá plantão no fim de semana). Ele chiava um pouco, mas eu já dei muitos plantões... talvez porque ele ficasse com a menina, além de ficar em casa. Talvez fosse pra casa da mãe dele, mas ainda tinha que ficar com minha filha pequena. Realmente, pra um homem ficar com uma criança, uma menina pequena, é complicado. Às vezes não tinha babá, então tinha coisas que ele... tinha que fazer (grifos nossos) (Denise, médica, 32 anos).

A história da cultura exerce enorme influência sobre o modo de ser mulher, mas, além do panorama cultural, a história individual é um fato importante na posição de sujeito que assumimos. Woodward, ao tentar compreender porque as pessoas assumem posições de identidade e se identificam com elas, chama a atenção para o nível psíquico. Para melhor explicitar essa questão, é necessário lançar mão de um outro termo, subjetividade, extremamente relacionado com o conceito de identidade, a ponto de muitas vezes ser usado de forma intercambiável (Woodward, 2000). Esse termo se relaciona com a maneira como compreendemos o nosso eu, como nós nos concebemos, com aquilo que pensamos que somos; envolve nossos pensamentos e sentimentos mais pessoais, tanto conscientes quanto inconscientes. Entretanto, diz a autora, 


\begin{abstract}
Nós vivemos nossa subjetividade em um contexto social no qual a linguagem e a cultura dão significado à experiência que temos de nós mesmos e no qual nós adotamos uma identidade. Quaisquer que sejam os conjuntos de significados construídos pelos discursos, eles só podem ser eficazes se eles nos recrutam como sujeitos. Os sujeitos são, assim, sujeitados ao discurso, e devem, eles próprios, assumi-lo como indivíduos que, dessa forma, se posicionam a si próprios (Woodward, 2000, p. 55)
\end{abstract}

É porque a subjetividade inclui as dimensões consciente e inconsciente que as identidades daí resultantes se apresentam como contraditórias. Esse conceito permite compreender o investimento pessoal que fazemos em determinadas posições específicas de sujeito, porque nos apegamos a identidades particulares. Como resultado dessas contradições, novas identidades ou novas formas de identificação podem emergir, se preferirmos enfatizar o processo de subjetivação em vez das práticas discursivas.

A identificação é um processo de articulação em que nunca há um ajuste completo, uma totalidade. (...) "Ela envolve um trabalho discursivo, o fechamento e a marcação de fronteiras simbólicas, a produção de 'efeitos de fronteiras.' Para consolidar o processo, ela requer aquilo que é deixado de fora o exterior que a constitui" (Hall, 2000, p. 106). Na identificação, aquilo que foi excluído, a mulher submissa, dedicada à vida privada, assombra, é ambivalente. As identificações não são, de nenhum modo, um sistema relacional coerente, pois nelas coexistem demandas que são diversas, conflituosas e desordenadas (Laplanche \& Pontalis, 1992).

Eu acho que eu queria muito casar, ter um marido que me ajudasse... Sustentasse (risos) (Talita, psicóloga, 26 anos).
Diante desse contexto, um modo de ser planejado e programado vem aparecendo com frequência nos discursos femininos. Cada coisa a seu tempo e no seu lugar. Parece não haver lugar para o imprevisível e, talvez, este venha a nos surpreender. Uma de nossas entrevistadas diz:

\begin{abstract}
As mulheres hoje preferem ter mais tarde uma família quando já tiverem conseguido uma posição na carreira, alcançar o que almejam, e depois é que elas constituem família (...). Eu acho que eu casei maravilhosamente bem: tive tempo de estudar, de sair, me divertir, e quando apareceu, apareceu na época ótima, porque eu já tinha meu trabalho, já tinha estudado, já tinha passeado e agora assumo as responsabilidades do casamento sem problema (Rosana, oficial de justiça, 31 anos).
\end{abstract}

Um fato que já se apresenta frequentemente, hoje, é a questão da procriação retardada, de mulheres que adiam a procriação para depois que tiverem alcançado outros objetivos. A esse respeito, Rosana diz:

Eu creio que, quando eu tiver filhos, a forma como eu administro minha vida não vai mudar muito não, porque eu sou muito organizada nestas coisas. Eu tô pretendendo ter filhos agora, eu já estou liberando e já vou planejando, organizando, então eu acho que não vai mudar muito, não (Rosana, oficial de Justiça, 31 anos).

Pesquisas vêm apontando que nem sempre as coisas funcionam como o esperado. Adiar a maternidade pode levar a mulher a ter dificuldades de engravidar e a necessitar lançar mão das novas tecnologias de procriação (Braga, 2005) ou da adoção. Mas todos esses fenômenos, longe de nos imobilizarem, nos desafiam, e, daí, novos modos de subjetivação poderão emergir. 


\section{Considerações Finais}

Como avaliar a identidade feminina, hoje? Ou melhor, como pensar sobre os modos de subjetivação femininos no mundo contemporâneo? Esses questionamentos não excluem a concepção de que a identidade é relacional, ou seja, que as identificações acontecem em um contexto de relações que inclui o um e o outro, o mais que um, que há sempre um a menos ou a mais, nunca uma totalidade. De fato, o jogo das identificações é sempre marcado pela diferença, acontece no limite, na fronteira, e sofre a marcação das fronteiras, uma vez que envolve um trabalho discursivo. Assim, quando falamos em mulher ou mulheres, não estamos colocando essa identidade em oposição à identidade masculina, como dois polos dicotômicos, mas tomando esse outro como um dos elementos que a constitui.

Nesse sentido, nós nos propomos a ver o gênero de uma forma pluralizada que escape à lógica binária, na qual um polo sempre se contrapõe ao outro. Essa perspectiva possibilita atentar para o fato de que mulheres e homens vivem suas feminilidades e masculinidades de maneiras diversificadas, nem sempre hegemônicas, nem sempre harmoniosas, mas, certamente, legítimas e com direito a serem representadas e reconhecidas.

Ao tomarmos por princípio que as identidades não são unificadas, naturalizadas, mas construções que resultam de nossas práticas históricas e discursivas, admitimos que elas são mutáveis. As mulheres que ouvimos nesta pesquisa confirmam esses pressupostos. Vivem em um momento histórico que lhes endereça discursos que as exortam a se posicionarem como sujeitos autônomos, livres, e o trabalho se apresenta como um dos meios de afirmação desse sujeito. Ao mesmo tempo, outros discursos thes são endereçados: o de mulheres/mães, esposas, donas de casa. Esses discursos são atravessados por outros que lhes indicam que não estão mais sozinhas nesses campos de atuação, mas que devem contar com um/a parceiro/a assim como com toda uma rede de apoio social constituída por profissionais e/ou familiares, multiplicidade de discursos e de possibilidades de subjetivação, não mais homens x mulheres, mas homens, mulheres, homossexuais femininas, masculinos, bissexuais e transexuais, entre outros. As identidades de gênero estão continuamente se transformando, e é necessário perceber que, ao discursarmos sobre elas, estamos também contribuindo para a sua construção.

Presenciamos o surgimento de novas possibilidades de ser sujeito. Reiterando que as identidades são relacionais e que as mudanças não acontecem de forma unilateral em um dado gênero, algumas possibilidades começam a delinear-se. Como exemplo, citamos os casais que se separam e adotam a guarda compartilhada dos filhos como forma de preservar tanto os laços parentais com os filhos quanto a vida profissional e certa independência de cada um dos cônjuges. Não é mais ponto pacífico que a guarda dos filhos caiba exclusivamente à mãe, tendo, inclusive aumentado o número de pais que reivindicam a guarda exclusiva de seus filhos. Um novo pai?

Outra possibilidade são os casais que optam por não ter filhos sem que isso signifique, necessariamente, uma atitude egoísta, e sim, um novo modo de ser sujeito que questiona normas anteriormente dadas como indiscutíveis, tais como "quem casa deve ter filhos". Borsa e Feil (2008) afirmam que, se o desejo de ter filhos não é propriamente uma novidade, a maternidade opcional é uma 
ruptura com ideais arcaicos de dedicação materna exclusiva e com a obrigação da maternidade. O modo singular como cada mulher se posiciona em relação a esse desejo pode reafirmar as normas antigas ou resistir a elas. Nesse sentido, pode-se pensar que o casal que não quer ter filhos faz parte de um movimento de resistência. Como diz Foucault (2006), onde há poder, há resistência. Embora possamos pensar também na possibilidade de esses casais estarem sendo influenciados por novos dispositivos de verdade que produzem discursos tais como: "O Planeta já está superpovoado; o mundo atual é violento demais para se criar um filho", entre outros. Foucault (2006) chama a nossa atenção para o fato de que aparentes contradições podem conviver, simultaneamente, em um duelo de forças, já que os discursos e as ações não possuem uma lógica linear de existência. De todo modo, é possível dizer que um casal que não deseja ter filhos se encontra na posição de produzir novas modalidades de subjetivação.

Na família atual, cada vez mais homens e mulheres circulam entre diferentes papéis e funções. Independentemente do fato de ter ou não filhos, os lugares ocupados por cada um dos gêneros deixaram de ser estabelecidos de modo rígido, fixo e imutável em função de seu sexo e dependem das contingências em que os casais estão inseridos.

\section{Maria Cristina Lopes de Almeida Amazonas}

Professora do Programa de Pós-Graduação em Psicologia Clínica da Universidade Católica de Pernambuco, Recife, Brasil. Doutora pela Universidade de Deusto, Bilbao, Espanha.

E-mail: crisamaz@elogica.com.br

\section{Luciana Leila Fontes Vieira}

Professora do Programa de Pós-Graduação em Psicologia Clínica da Universidade Católica de Pernambuco,

Doutora em Saúde Coletiva pelo IMS/UERJ, Rio de Janeiro - RJ - Brasil.

E-mail: lufontesvieira@hotmail.com

\section{Virgínia Cavalcanti Pinto}

Mestre em Psicologia Clínica pela Universidade Católica de Pernambuco, Pernambuco - PE - Brasil.

E-mail: giniapinto@yahoo.com.br

Endereço para envio de correspondência:

Rua Regueira Costa, 75, apto 701, Rosarinho, Recife - PE - Brasil. CEP: 52041-050 


\section{Referências}

Arán, M. (2006). O avesso do avesso: feminilidade e novas formas de subjetivação. Rio de Janeiro: Garamond.

Araújo, C., \& Scalon, C. (2006). Gênero e a distância entre a intenção e o gesto. Revista Brasileira de Ciências Sociais, 21(62), 45-63.

Borsa, J. C., \& Feil, C. F. (2008). O papel da mulher no contexto familiar: uma breve reflexão. Recuperado em 13 de junho de 2008, de Psicologia.com.pt. O portal dos psicólogos. www. psicologia.com.pt.

Braga, M. G. R. (2005). Maternidade e tecnologias de procriação: o feminino na contemporaneidade. Dissertação de mestrado, Programa de Pós-Graduação em Psicologia Clínica, Universidade Católica de Pernambuco, Recife, PE.

Bruschini, M. C. A. (2007). Trabalho e gênero no Brasil nos últimos dez anos. Cadernos de Pesquisa, 37(132), 537-572.

Butler, J. (2001). Corpos que pesam: sobre os limites discursivos do "sexo". In G. L. Louro (Org.), O corpo educado: pedagogias da sexualidade (pp.150-172). Belo Horizonte, MG: Autêntica.

Butler, J. (2003). Problemas de gênero: feminismo e subversão da identidade. Rio de Janeiro: Civilização Brasileira.

Castro, E. (2009). Vocabulário de Foucault: um percurso pelos seus temas, conceitos e autores. (I. M. Xavier, trad.) Belo Horizonte, MG: Autêntica.

Ellsworth, E. (2001). Modos de endereçamento: uma coisa de cinema; uma coisa de educação também. In T. T. da Silva (Org.), Nunca fomos humanos: nos rastros do sujeito (pp. 7-76). Belo Horizonte, MG: Autêntica.

Foucault, M. (2006). Microfísica do poder. Rio de Janeiro: Edições Graal. (Trabalho original publicado em 1979)

Foucault, M. (2009). Vigiar e punir: nascimento da prisão. Petrópolis, RJ: Vozes. (Trabalho original publicada em 1977)

Hall, S. (2000). Quem precisa da identidade? In T. T. Silva (Org.), Identidade e diferença: a perspectiva dos estudos culturais (pp. 103-133). Petrópolis, RJ: Vozes.
Jablonski, B. (2010). A divisão de tarefas domésticas entre homens e mulheres no cotidiano do casamento. Psicologia: Ciência e Profissão, 30 (2), 262-275.

Laplanche, J., \& Pontalis, J. B. (1992). Vocabulário da psicanálise. São Paulo: Martins Fontes.

Louro, G. L. (2003). Gênero, sexualidade e educação: uma perspectiva pós-estruturalista. Petrópolis, RJ: Vozes.

Louro, G. L. (2008). Gênero e sexualidade: pedagogias contemporâneas. Pro-Posições, 19( 2), 17-23.

Meyer, D. E. (2003). Educação, saúde e modos de inscrever uma forma de maternidade nos corpos femininos. Movimento, 9(3), 33-58.

Minayo, M. C. S. (1999). O desafio do conhecimento: pesquisa qualitativa em saúde. São Paulo: Hucitec; Rio de Janeiro: Abrasco.

Narvaz, M. G., \& Koller, S. H. (2007) A marginalização dos estudos feministas e de gênero na psicologia acadêmica contemporânea. Psico, 38(3), 216-223.

Prins, B., \& Meijer, I. C. (2002). Como os corpos se tornam matéria: entrevista com Judith Butler. Revista Estudos Feministas, 10(1), 155-167.

Scott, J. (2005). O enigma da igualdade. Revista Estudos Feministas, 13(1), 11-30.

Woodward, K. (2000). Identidade e diferença: uma introdução teórica e conceitual. In T. T. Silva (Org.), Identidade e diferença: a perspectiva dos estudos culturais (pp. 7-72). Petrópolis, RJ: Vozes. 